\title{
Syphilis: using modern approaches to understand an old disease
}

\author{
Emily L. Ho ${ }^{1}$ and Sheila A. Lukehart ${ }^{2,3}$ \\ 1Department of Neurology, ${ }^{2}$ Department of Medicine, and ${ }^{3}$ Department of Global Health, \\ University of Washington School of Medicine, Seattle, Washington, USA.
}

\begin{abstract}
Syphilis is a fascinating and perplexing infection, with protean clinical manifestations and both diagnostic and management ambiguities. Treponema pallidum subsp. pallidum, the agent of syphilis, is challenging to study in part because it cannot be cultured or genetically manipulated. Here, we review recent progress in the application of modern molecular techniques to understanding the biological basis of this multistage disease and to the development of new tools for diagnosis, for predicting efficacy of treatment with alternative antibiotics, and for studying the transmission of infection through population networks.
\end{abstract}

\section{Treponema pallidum - the causative agent}

Treponema pallidum subsp. pallidum (T. pallidum) is a spirochete that, while able to persist for decades in the mammalian host, is extremely fragile ex vivo. It can be cultured only transiently in vitro in rabbit epithelial cells and must be propagated in rabbits to maintain strains for laboratory examination. Consequently, genetic manipulation of this organism is not yet possible. In addition, the limited repertoire of immunological reagents available for rabbits adds to the challenges of studying immune responses to this organism.

Analysis of the T. pallidum genome reveals a notable absence of metabolic capability (1). T. pallidum has the genes encoding enzymes involved in glycolysis but lacks those related to the tricarboxylic acid cycle and the electron transport system. Similarly, it lacks most genes associated with synthesis of nucleotides, amino acids, and lipids. The genome encodes for multiple transport proteins, indicating that it may rely heavily on scavenging required compounds from its human host (1).

Despite the difficulties in working with $T$. pallidum, much has been learned about the molecular basis of syphilis pathogenesis. For each stage of infection, we review the most closely related steps of pathogenesis.

\section{The natural history of syphilis}

Primary syphilis - transmission, adhesion, local host immune response. T. pallidum is usually transmitted sexually through microabrasions in mucosal membranes or skin and rapidly enters the bloodstream to disseminate to other tissues. T. pallidum can be identified by PCR in the bloodstream of patients with all stages of syphilis, and the quantity of treponemes in blood is highest during early syphilis $(2,3)$. Individuals with lesions of early syphilis are most likely to transmit T. pallidum. While the risk of infection in exposed individuals is approximately $30 \%$ (range, $10 \%-80 \%$ ) (4-6), inoculation studies with the Nichols strain of T. pallidum suggest that the intradermal $\mathrm{ID}_{50}$ is only 57 organisms (7). The natural history of T. pallidum infection is summarized in Figure 1.

To establish infection, T. pallidum adheres to epithelial cells and extracellular matrix components of the skin and mucosa. Several T. pallidum proteins mediate adherence, including TP0155 and

Conflict of interest: Sheila A. Lukehart is receiving research support from Cempra Pharmaceuticals.

Citation for this article: J Clin Invest. 2011;121(12):4584-4592. doi:10.1172/JCI57173.
TP0483, which bind to matrix fibronectin and to both soluble and matrix forms of fibronectin, respectively (8). TP0136, a protein identified by reactivity with primary human syphilitic sera (9), also binds to human fibronectin (10). TP0751 can bind to laminin, which has the highest concentration in the basement membrane (11-13), and to fibrinogen, a blood-clotting protein that functions to contain bacteria (13). TP0751 can also degrade laminin and fibrinogen using its zinc-dependent protease domain, which may be a means by which T. pallidum disseminates to surrounding tissues and the bloodstream (13).

T. pallidum replicates at the site of initial inoculation, dividing once every $30-33$ hours $(14,15)$, inducing a local inflammatory response that results in a painless chancre approximately 3-6 weeks after initial infection. In each chancre, proliferating spirochetes are surrounded by immune cells, including $\mathrm{CD}^{+}$and $\mathrm{CD}^{+} \mathrm{T}$ cells, plasma cells, and macrophages, which produce IL-2 and IFN- $\gamma$ cytokines, indicating a Th1-skewed response (16-21). Tissue necrosis and ulceration occur due to small vessel vasculitis, and trafficking immune cells cause a non-tender regional lymphadenopathy. Within 3-8 weeks, the chancre heals, indicating clearance of T. pallidum locally. However, by this time, T. pallidum has spread systemically to multiple tissues and organs, setting the stage for secondary syphilis.

Secondary syphilis - motility, systemic host immune response, diagnosis, systemic spread. T. pallidum propels itself using a corkscrew-like mechanism by rotating around its longitudinal axis, using endoflagella contained within the periplasmic space between the cytoplasmic membrane and the outer membrane (22-24). T. pallidum traverses the tight junctions between endothelial cells $(25,26)$ to enter the perivascular spaces, where large numbers of treponemes and immune cells accumulate. Based on electron microscopy images of secondary syphilis skin lesions, T. pallidum may also use transcytosis to spread through the endothelium (27). T. pallidum can induce the production of MMP-1 (28), which degrades collagen and may facilitate access to and egress from the bloodstream, resulting in systemic spread.

Usually within 3 months of infection, symptoms of secondary syphilis appear. The most common clinical manifestation is a disseminated maculopapular rash. Additional symptoms may include malaise, weight loss, muscle aches, generalized lymphadenopathy, patchy alopecia, meningitis, ocular inflammation, mucous patches (localized inflammation of mucosal tissues in 


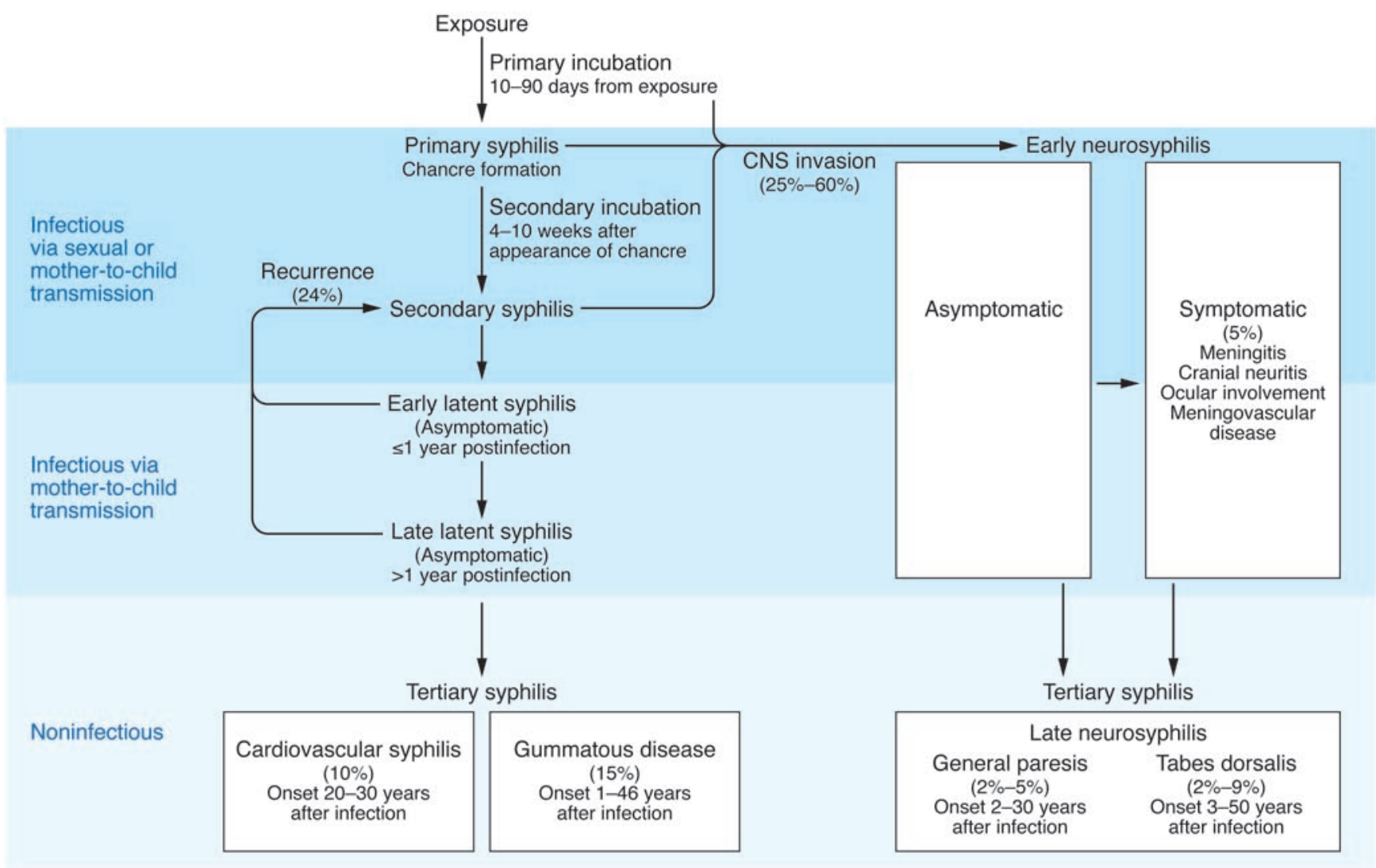

\section{Figure 1}

The natural history of untreated syphilis in immunocompetent individuals. Percentages of individuals developing to specific stages as well as time intervals are based on information in references 137, 146, and 147 (based on data from refs. 146-148).

the oral cavity and genitals), hepatitis, and gastric dysmotility $(29,30)$, reflecting T. pallidum invasion and the resulting immune cell infiltration of these tissues.

Although T. pallidum has structural similarities to classical Gramnegative bacteria, such as having outer and inner membranes and a periplasmic space, it lacks lipopolysaccharide, a potent proinflammatory glycolipid, and does not produce any known toxic proteins. Therefore, most of the symptoms and tissue damage related to syphilis are due to activation of the host inflammatory and immune responses. Exposure to whole T. pallidum and its lipoprotein TpN47 can induce expression of the adhesion molecules ICAM-1, VCAM-1, and E-selectin $(25,31)$, which are important in adhesion of immune cells to vascular endothelium for migration into sites of infected tissue. Patients with secondary syphilis have a local immune response in the skin, consisting of monocytes, macrophages, $\mathrm{CD}^{+}$and $\mathrm{CD}^{+} \mathrm{T}$ cells, and DCs (32-34). This proinflammatory response is due to the lipid moiety contained on the many lipoproteins of T. pallidum $(35,36)$. Early syphilis lesions transiently contain scant polymorphonuclear leukocytes (PMNs) (37), and injection of recombinant T. pallidum lipoproteins TpN17 (TP0435) and TpN47 (TP0574) into the dermis can induce transient infiltration of PMNs $(35,38)$, as well as a local enrichment of monocytes, macrophages, memory T cells, and DCs $(38,39)$.

The interaction of TpN47 with TLR2 on the surface of macrophages induces the production of IL-12 (40). When DCs are exposed to T. pallidum or purified T $\mathrm{pN} 47$, they release inflam- matory cytokines, such as IL- $1 \beta$, IL-6, IL-12, and TNF- $\alpha$ (41), and express maturation markers, including CD54, CD83, and MHC class II $(38,39,41-43)$. T. pallidum lipoproteins also stimulate macrophages and DCs by binding CD14, which transmits activation signals through the TLR1/TLR2 heterodimer $(40,44,45)$. The miniferritin $\mathrm{TpF} 1$ stimulates human monocytes to release IL-10 and TGF- $\beta$, which are key cytokines that promote Treg differentiation and may also allow long-term persistence of T. pallidum in the human host (46). $\mathrm{CD}^{+} \mathrm{T}$ cells present in the skin colocalize with staining for IFN- $\gamma$, perforin, and granzyme B (32), as well as IL-17 (34). Studies of lesional skin samples from patients with secondary syphilis show that plasma cells appear later (34).

The humoral immune response produces antibodies that function in opsonization (47) and complement-mediated immobilization or neutralization $(48,49)$. Macrophages clear T. pallidum from sites of infection through phagocytosis of opsonized organism (47, $50)$ using both IgG and IgM antibodies $(51,52)$. A study using an array of 882 polypeptides predicted to be in the T.pallidum proteome identified 106 proteins that could induce a detectable antibody response (53). Two T. pallidum lipoproteins that induce high titers of antibodies are $\mathrm{T} \mathrm{pN} 17$ and $\mathrm{TpN} 47$ (54-57), both of which are used in new enzyme and chemiluminescence immunoassay (EIA/CIA) serological tests for syphilis. Genome analysis of T. pallidum predicts that there are as many as 22 putative lipoproteins in the organism (1).

Measurement of antibodies is important for screening and diagnosis of syphilis. Two categories of antibodies - termed 
"non-treponemal," which are directed against phospholipids, and "treponemal," which are directed against T. pallidum polypeptides - have been used for this purpose. The non-treponemal antibodies are detected by the rapid plasma reagin (RPR) test, the Venereal Disease Research Laboratory (VDRL) test, and the toluidine red unheated serum test (TRUST). Treponemal antibodies are detected by immunofluorescence in the fluorescent treponemal antibody-absorbed (FTA-ABS) test or by agglutination in the T. pallidum hemagglutination (TPHA) or T. pallidum particle agglutination (TP-PA) test.

Traditionally, T. pallidum infection has been diagnosed using a non-treponemal screening test, with reactive results confirmed using treponemal serologic tests. Rapid point-of-care tests (58), EIAs (59), and CIAs $(60,61)$ have been developed that detect antitreponemal IgM and IgG antibodies, usually to recombinant T. pallidum proteins. The EIA/CIA tests can be automated, which has led some large laboratories in the United States to use revised syphilis screening algorithms beginning with a treponemal test. Positive tests are subsequently confirmed with a non-treponemal test, and discordant sera must be retested with a traditional treponemal test. One disadvantage of these newer tests is that they cannot distinguish between recent and remote syphilis, or between treated and untreated infection. In addition, because the new EIA/CIA tests are more sensitive than the fluorescence or agglutination tests, many sera that are reactive in the EIA/CIA tests are nonreactive in the confirmatory non-treponemal tests, particularly in low-risk populations such as pregnant women (62). These results have led to concerns about the specificity of the antigens used in these tests for syphilis infection. Indeed, a published study (63) reports that persons with periodontal disease carry oral treponemes that can be detected with monoclonal antibodies to the same TpN47 antigen used in many EIA/CIA tests. Persons with periodontal disease have detectable antibodies to this and other T. pallidum antigens. Additional related concerns regarding screening with automated treponemal tests include increased health care and public health costs caused by follow-up of unconfirmed EIA/CIA screening.

In the rabbit model, despite the presence of functional antibodies, passive immunization with immune serum fails to provide protective immunity against T. pallidum infection (64), demonstrating that cellular immunity is also required for protection. The link between humoral and cellular immunity in humans is indicated in studies of human PBMCs exposed in vitro to T. pallidum: internalization of treponemes by macrophages is facilitated by human syphilitic serum, leading to secretion of TNF- $\alpha$, IL-6, and IL- $1 \beta$ by macrophages and resulting in IFN- $\gamma$ production by NK cells, NK T cells, and T cells (65). After most T. pallidum have been cleared in the rabbit infection model, a few organisms remain and are able to resist macrophage ingestion even in the presence of immune serum (66), suggesting this subpopulation may be able to avoid opsonic antibody, persisting to cause latent or later stages of infection.

Early CNS invasion and neurological involvement. While CNS involvement of syphilis infection is classically considered as the tertiary stage of infection, invasion of the nervous system by T. pallidum and neurosyphilis occur within days or weeks of infection. Neurosyphilis is diagnosed by clinical manifestations (see below) as well as by cerebrospinal fluid (CSF) abnormalities such as elevated white blood cell (wbc) count, elevated CSF protein, or reactive CSF-VDRL test. Many affected patients may be asymptomatic in spite of the presence of abnormal CSF.
While most patients with CNS infection appear to control or clear CNS infection by T. pallidum, the factors underlying the subsequent development of symptomatic neurosyphilis in some patients are not known. Symptomatic and asymptomatic neurosyphilis are more common when the serum RPR titer is $1: 32$ or greater regardless of HIV status, or in HIV-infected individuals when the peripheral blood $\mathrm{CD}^{+} \mathrm{T}$ cell count is 350 or fewer cells/ $\mu \mathrm{l}(67-70)$.

Symptoms of early neurosyphilis may occur during or following the primary or secondary stages of syphilis, especially in HIV-infected individuals (71) and include meningitis (headache, fever, and stiff neck), visual changes (blurred vision, loss of vision, photophobia, and other signs of ocular inflammation), hearing changes or loss, and facial weakness. Some studies indicate that HIV-infected individuals may have more significant symptoms of neurosyphilis (72), and HIV-infected individuals who have symptomatic neurosyphilis have more severe CSF abnormalities (70, 73). Treatment of HIV-infected patients with antiretroviral therapy (ART) decreases the chance of developing neurosyphilis by $65 \%$ (70), suggesting that immune reconstitution with ART may result in an improved local immune response against T. pallidum and better control of the infection.

Diagnosis of asymptomatic neurosyphilis is complicated by the fact that none of the CSF measures currently used is very sensitive (CSF-VDRL) or specific (CSF wbc, CSF protein). In addition, concurrent HIV infection itself may cause an elevated CSF wbc count or protein concentration. A recently described adjunct diagnostic marker for neurosyphilis is the B cell chemokine CXCL13 (74).

Latent and tertiary syphilis - antigenic variation and persistence. Despite a host immune response that results in effective local clearance of T. pallidum from primary and secondary lesions, treponemes persist in many tissues without causing clinical signs or symptoms. This is termed the latent stage. While T. pallidum may seed the bloodstream intermittently during the latent stage and thus infect a developing fetus during pregnancy, sexual transmission is rare.

How can T. pallidum "escape" immune detection to cause persistent and later stages of infection? Recent evidence suggests that T. pallidum organisms may be able to evade the acquired immune response by antigenic variation of bacterial surface proteins, consistent with the resistance to phagocytosis of those select treponemes that survive bacterial clearance of the primary lesion (51). Antigenic variation is well described in related spirochetes that cause relapsing fever (Borrelia hermsii) and Lyme disease (Borrelia burgdorferi), each of which also has a multistage clinical course $(75,76)$.

Although $T$. pallidum has few integral outer membrane proteins $(23,24,77,78)$, bioinformatic approaches have identified several candidates, including members of the family of $12 \mathrm{~T}$. pallidum repeat (Tpr) proteins $(79,80)$. Among Tpr family members, TprK is the best studied. A strong antibody and $\mathrm{T}$ cell immune response is elicited against $\operatorname{TprK}(81,82)$, and immunization with recombinant TprK provides partial immunity against infectious challenge $(80,83)$. Antibodies raised against recombinant TprK can opsonize T. pallidum for phagocytosis by macrophages in vitro (80). TprK sequences differ substantially between and within individual strains (84-86), and this diversity is localized to seven discrete variable regions of the protein, which are predicted to be surface exposed. TprK sequence diversity accumulates following development of acquired immunity in the rabbit model $(86,87)$. Molecular studies of TprK show that new variants arise by segmental gene conversion, with the new sequences coming from a large repertoire of "donor sites" located elsewhere on the chromosome 


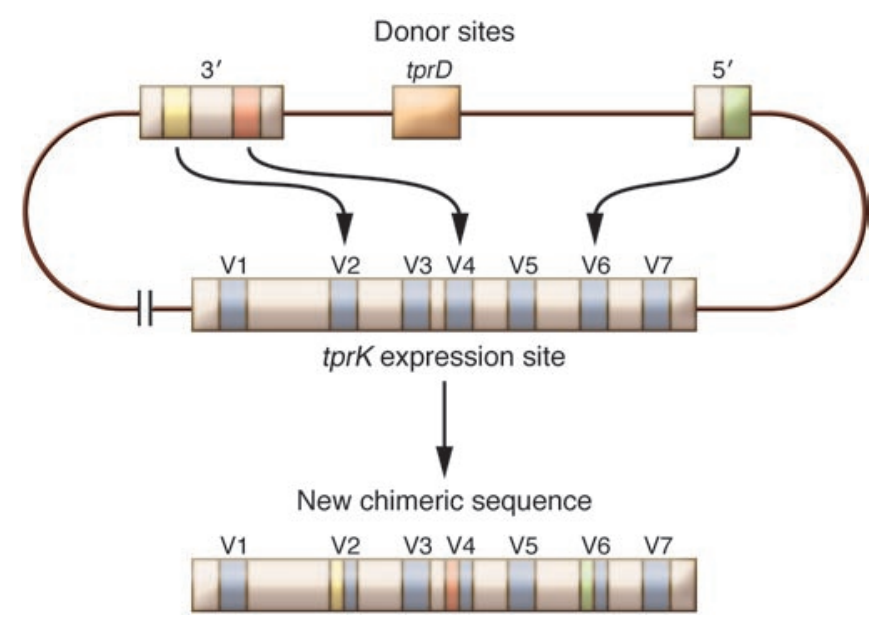

Figure 2

Gene conversion as the mechanism of antigenic variation of TprK in T. pallidum. Variant DNA segments located adjacent to the tprD gene non-reciprocally recombine with the variable regions (V1-V7) of the tprK gene in the expression site to generate new TprK mosaic proteins.

(ref. 88 and Figure 2). The resulting changes in exposed variable regions of TprK enable the organism to evade antibody binding and opsonophagocytosis (89). These TprK variant treponemes survive clearance and persist during chronic latent infection.

In some individuals, chronic latent infection can reactivate to cause tertiary syphilis, which occurs years to decades after initial infection and can affect multiple organs. In a retrospective study of patients from Oslo in the pre-antibiotic era, approximately onethird of patients with untreated latent syphilis developed tertiary syphilis (90). Manifestations may include gumma, cardiovascular syphilis, and tertiary neurosyphilis. In the modern antibiotic era, tertiary syphilis is rarely seen, perhaps due to inadvertent syphilis treatment with antibiotics prescribed for other infections.

\section{HIV and syphilis}

Since the beginning of HIV/AIDS epidemic, there has been a high rate of HIV-1 (HIV) coinfection among syphilis patients. In 2002, the CDC reported that $25 \%$ of primary and secondary syphilis cases occurred in persons coinfected with HIV, and the incidence rate of syphilis in HIV-infected persons was 77 times greater than in the general population (91). The number of cases of early syphilis has continued to rise over the past decade in all geographic regions, particularly in men who have sex with men (MSM), and over the past 5 years in both African American men and women (92). While the increasing incidence of syphilis may be due to high risk behaviors (93-95), higher rates of syphilis and HIV coinfection may also be due to immunological and bacteriological factors.

The primary chancre can facilitate acquisition and transmission of HIV by disrupting mucosal and epithelial barriers (96). In addition, the influx of immune cells to syphilis lesions increases the number of cellular targets available for HIV infection and the proximity of HIV-infected cells to transmit virus to the partner. T. pallidum itself and T. pallidum lipoproteins increase the expression of CCR5, the chemokine receptor expressed on macrophages and DCs that acts as a coreceptor for HIV entry into CD4 $4^{+}$cells $(33,97)$.

It is not clear whether HIV coinfection worsens clinical manifestations of early syphilis or neurosyphilis. However, clinical and CSF abnormalities consistent with neurosyphilis are more common in $\mathrm{HIV}$-infected individuals with $\mathrm{CD}^{+} \mathrm{T}$ cell counts less than or equal to 350 cells $/ \mathrm{ml}(67,69,98)$. HIV-infected individuals with neurosyphilis have higher CSF HIV RNA concentrations, suggesting there may be an interaction between syphilis and HIV in the CNS (99).

While the long-term consequences of syphilis infection on the HIV-infected individual's prognosis are not known, one prospective study suggests that despite transient increases in $\mathrm{CD}^{+}$ T cell counts and viral loads, syphilis did not appear to affect HIV progression (100). T. pallidum coinfection may have a deleterious impact on the immunologic and virologic status in HIV-infected persons, which may improve with syphilis treatment, although these data are conflicting (101-104).

\section{Treatment}

For more than 50 years, parenteral penicillin has been used successfully to treat individuals with syphilis, with clinical resolution and prevention of sexual transmission. Thus, it remains the treatment of choice for syphilis, and no penicillin-resistant strains have yet been documented. Benzathine penicillin G (BPG), a depot form, is used for standard treatment of syphilis, and aqueous penicillin is used for persons with recognized neurosyphilis. Unlike aqueous penicillin, BPG does not cross the blood-brain barrier to reach T. pallidum that may have invaded the CNS. This is of particular concern for HIV-infected persons with syphilis.

Patients with HIV have increased rates of serological failure of syphilis treatment (105-107), and viable T. pallidum have been isolated from the CSF of HIV-infected patients following standard treatment for syphilis $(105,106,108)$. In addition, HIVinfected individuals with neurosyphilis are less likely to achieve normal CSF laboratory values $(70,109)$ and may take longer to resolve CSF abnormalities following treatment, compared with HIV-uninfected individuals $(70,109,110)$. Effective ART has been associated with a reduction in the rate of serologic failure for syphilis (70).

Despite these concerns, the CDC currently recommends that HIV-infected individuals undergo the same BPG treatment for syphilis as HIV-uninfected individuals, and that evidence of neurosyphilis (i.e., CSF examination) not be sought in patients without neurological signs or symptoms regardless of HIV status (92). The long-term repercussions of these recommendations for CSF examination are unclear at this time.

Alternative oral antibiotic treatments. Macrolides, such as erythromycin and azithromycin, and tetracycline antibiotics, such as tetracycline and doxycycline, are alternatives to parenteral penicillin in non-pregnant penicillin-allergic patients. Tetracycline, doxycycline, and erythromycin require multiple doses daily for 2-4 weeks, reducing likelihood of patient compliance. In contrast, azithromycin provides a single-dose oral alternative to parenteral BPG for early syphilis. Early syphilis has been successfully treated with a single 1- to 2-g dose of oral azithromycin (111-116) with efficacy equal to that of BPG.

Unfortunately, with increased use of azithromycin for many infections, there has been an alarming rise in the prevalence of macrolide-resistant T. pallidum. The first macrolide-resistant strain of T. pallidum (Street strain 14) was isolated in $1977(117,118)$, and no other such resistant strains were reported until 2004. Street strain 14 is highly resistant to both erythromycin and azithromycin $(117,119)$ by virtue of an adenine-to-guanine $(A \rightarrow G)$ mutation at the position cognate to A2058 in the E. coli $23 \mathrm{~S}$ rRNA gene 


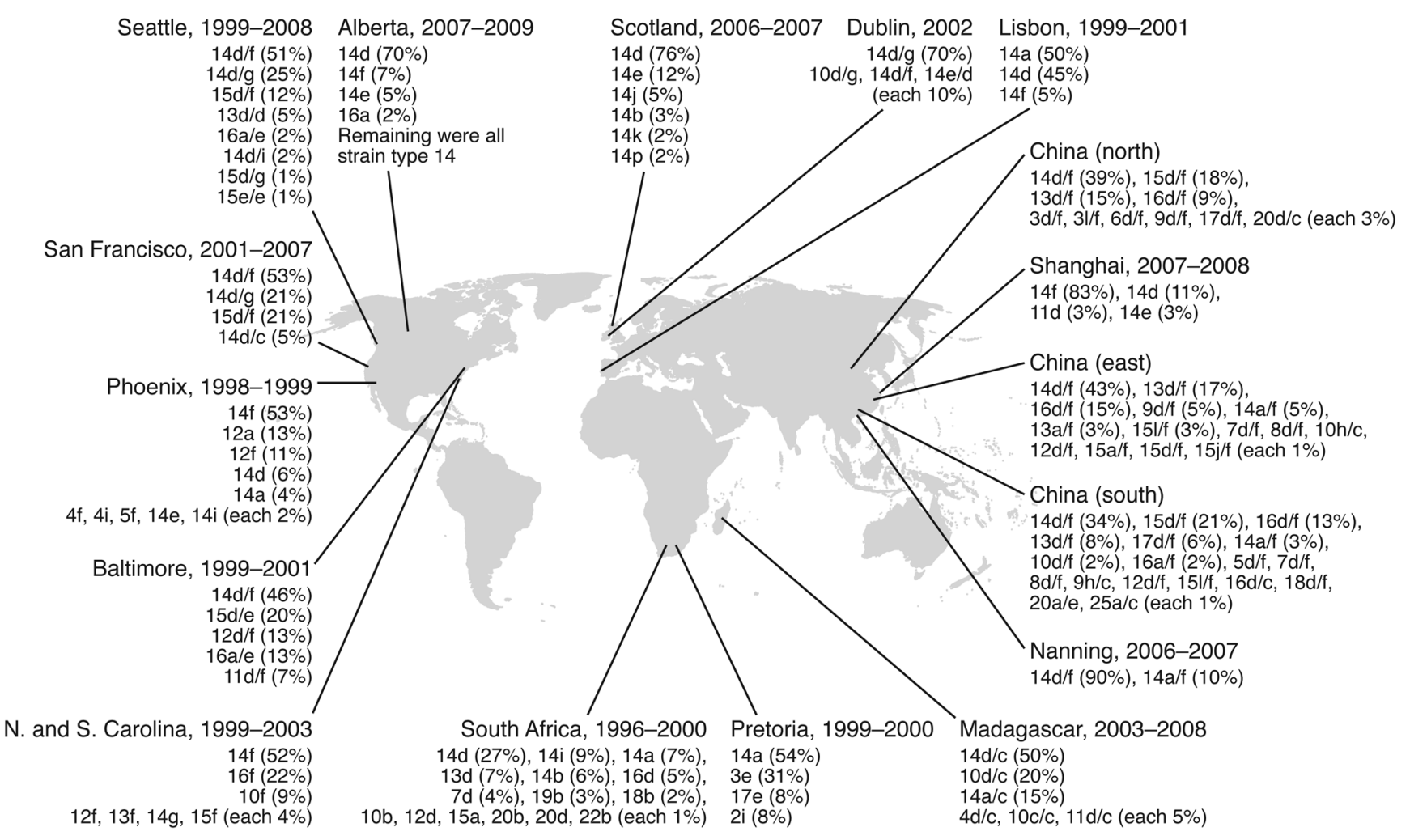

Figure 3

T. pallidum strain types identified throughout the world. The strain type information, years of collection, and the frequency of each strain type from each location are based on information in references 126, 127, 129-131, 133-135, 149, and 150.

(120). Clinical failures following azithromycin treatment in San Francisco triggered examination of $T$. pallidum strains from several geographical regions, revealing the presence of the A2058G mutation in $11 \%-88 \%$ of T. pallidum samples $(121,122)$. In San Francisco and Seattle, the prevalence of this mutation has increased steadily over time (121-123). In 2009, a new mutation, A2059G, was identified in the 23S rRNA gene in T. pallidum recovered from a patient from the Czech Republic who failed treatment with spiramycin, a macrolide antibiotic (124); this mutation also confers resistance to erythromycin, azithromycin, and spiramycin. Zhou and colleagues reported treatment failure in 132 patients who received azithromycin for syphilis in Shanghai from 2001 to 2008 (125), but the proportion of patients infected with T. pallidum harboring the A2058G or A2059G mutations was not reported. Three published trials of successful azithromycin treatment of syphilis in Africa have led some to conclude that macrolide-resistant strains are not present in Africa. Of note, patients were enrolled in these studies in 1994-1997, 2000-2003, and 2000-2007 (114-116), either before or very early after recognition of macrolide-resistant strains elsewhere in the world. Although there are no recent data from Africa on macrolide resistance, the absence of it does not imply the absence of resistant strains.

Although a global surveillance program for macrolide resistance mutations has not been developed for T. pallidum, the scattered reports from many continents suggest that these resistant strains are widespread, and strong caution is advised in contemplating the use of azithromycin for treating syphilis.

\section{Molecular strain typing of $T$. pallidum}

The ability to uncover important information about networks of transmission of syphilis infection and, particularly, to understand the development and spread of antibiotic-resistant strains requires a method for differentiating one strain of T. pallidum from another. Pillay and colleagues developed a T. pallidum typing method based on (a) determination of the number of 60 -bp repeats in the acidic repeat protein (arp) gene and (b) sequence differences in the Tpr subfamily II genes (tprE [tp0313], tprG [tp0317], and tprJ [tp0621]) determined by restriction fragment length polymorphism (RFLP) analysis (126). T. pallidum subtypes with a range of 2 to 21 ARP repeats and 7 different RFLP patterns, designated $a-g$, have been described (126). This method for subtype designation has been applied to patient samples taken from chancres, condyloma lata, mouth scrapings, ear lobe scrapings, blood, CSF, and laboratory-passaged T. pallidum isolates from diverse geographic areas (126-134). Epidemiological studies of strain types in San Francisco and Seattle in the last decade showed that most are subtype 14d $(123,135)$, which may suggest a linked sexual network, while other studies indicate variation in the distribution of predominant strain types by location in the United States and worldwide (refs. 127-131, 133, 134, and Figure 3). Addition of a third gene to the typing scheme increased discriminatory power $(123,135)$. Subtyping using the tp0548 gene demonstrated that the predominant $14 \mathrm{~d} / \mathrm{f}$ strain was replaced by the $14 \mathrm{~d} / \mathrm{g}$ strain in Seattle during the period from 1999 to 2008 (135). This recognition would not have been possible with the two-target typing method. 
Molecular analysis can also be used to determine whether macrolide-resistant $T$. pallidum represents a single strain or whether resistance has spontaneously arisen in multiple strains. The A2058G mutation was found in molecularly separate strains in Seattle, suggesting that resistance mutations are arising spontaneously, rather than representing a single strain spreading throughout a population. Resistant strains were more likely to be found in patients who had received macrolide antibiotics in the previous 12 months $(123,136)$.

Strain typing may also be used to identify strains that are associated with particular clinical outcomes. Clinical descriptions from the pre-antibiotic era (137) and studies in the rabbit infection model suggest that some strains are more prone to neuroinvasion (138). A recent study of T. pallidum showed that patients infected with strain type $14 \mathrm{~d} / \mathrm{f}$ had a higher rate of neurosyphilis compared with patients infected with other strain types (135).

\section{Vaccine development and prevention}

Although highly effective treatment is available for syphilis, currently, there is an epidemic of syphilis in China and increasing incidence in the United States and Europe. The best hope for control of syphilis is development of a vaccine that prevents both disease and transmission. Attempts have been made over many decades to produce a successful syphilis vaccine by immunizing rabbits with whole killed or attenuated T. pallidum (reviewed in refs. 139 and 140). Only one immunization study, using multiple intravenous doses of gamma-irradiated T. pallidum, demonstrated complete protection against infectious challenges in the rabbit model (141). This protocol was very cumbersome and expensive, and impractical to test in humans. Immunization with recombinant $T$. pallidum antigens can stimulate production of an immune response in the rabbit model, resulting in only partial protection, with significantly attenuated lesion development but no sterile immunity $(80,83,142-145)$. The discovery of antigenic variation in TprK makes the development of a protective vaccine even more formidable. However, studies are underway to test the ability of a cocktail of conserved regions of T. pallidum antigens to confer protection in the rabbit model.

\section{Conclusion}

Syphilis is one of the oldest recognized sexually transmitted infections, and despite the availability of inexpensive and effective therapy, the incidence is increasing in many parts of the world. T. pallidum is a challenging infectious agent to study because of its inability to be cultured or genetically manipulated, its physical fragility, and its outbred animal model. Despite these challenges, development of highly discriminating molecular methods for strain differentiation will provide insights into the transmission of this infection through populations, perhaps suggesting new ways to target intervention activities. In addition, our knowledge of the molecular pathogenesis of syphilis has expanded vastly during the past decade, especially with respect to understanding the host immune response to T. pallidum. Work on this fascinating organism continues to focus on understanding its ability to evade host immune responses, which may ultimately lead to the development of a successful vaccine.

\section{Acknowledgments}

The authors thank Christina Marra and Lauren Tantalo for critical reading of the manuscript and Lorenzo Giacani for helpful discussions. We apologize to those authors whose work we were unable to cite because of space limitations. This work was supported by U.S. Public Health Service grants R01 AI63940, R01 AI42143, and R03 AI094122 (to S.A. Lukehart) from the NIH. E.L. Ho was supported by University of Washington STD and HIV Research Training Grant T32 AI007140.

Address correspondence to: Sheila A. Lukehart, Department of Medicine, Box 359779, Harborview Medical Center, 325 9th Avenue, Seattle, Washington 98104, USA. Phone: 206.897.5362; Fax: 206.897.5363; E-mail: lukehart@u.washington.edu.
1. Fraser CM, et al. Complete genome sequence of Treponema pallidum, the syphilis spirochete. Science. 1998;281(5375):375-388.

2. Cruz AR, et al. Secondary syphilis in Cali, Colombia: new concepts in disease pathogenesis. PLoS Negl Trop Dis. 2010;4(5):e690.

3. Tipple C, et al. Getting the measure of syphilis: qPCR to better understand early infection. Sex Transm Infect. 2011;87(6):479-485.

4. Schroeter AL, Turner RH, Lucas JB, Brown WJ. Therapy for incubating syphilis. Effectiveness of gonorrhea treatment. JAMA. 1971;218(5):711-713.

5. Alexander LJ, Schoch AG, Mantooth WB. Abortive treatment of syphilis; results obtained in the incubation, primary, and secondary stages of syphilis. Am J Syph Gonorrhea Vener Dis. 1949;33(5):429-436.

6. Schober PC, Gabriel G, White P, Felton WF, Thin RN. How infectious is syphilis? BrJ Vener Dis. 1983; 59(4):217-219.

7. Magnuson HJ, Thomas EW, Olansky S, Kaplan BI, DeMello L, Cutler JC. Inoculation syphilis in human volunteers. Medicine. 1956;35(1):33-82.

8. Cameron CE, Brown EL, Kuroiwa JM, Schnapp LM, Brouwer NL. Treponema pallidum fibronectin-binding proteins. J Bacteriol. 2004;186(20):7019-7022.

9. Brinkman $\mathrm{MB}$, et al. Reactivity of antibodies from syphilis patients to a protein array representing the Treponema pallidum proteome. J Clin Microbiol. 2006;44(3):888-891.

10. Brinkman MB, et al. A novel Treponema pallidum antigen, TP0136, is an outer membrane protein that binds human fibronectin. Infect Immun. 2008; 76(5):1848-1857.

11. Cameron CE. Identification of a Treponema palli dum laminin-binding protein. Infect Immun. 2003; 71(5):2525-2533.

12. Cameron CE, Brouwer NL, Tisch LM, Kuroiwa JM. Defining the interaction of the Treponema pallidum adhesin Tp0751 with laminin. Infect Immun. 2005;73(11):7485-7494.

13. Houston S, Hof R, Francescutti T, Hawkes A, Boulanger MJ, Cameron CE. Bifunctional role of the Treponema pallidum extracellular matrix binding adhesin Tp0751. Infect Immun. 2011;79(3):1386-1398.

14. Cumberland MC, Turner TB. The rate of multiplication of Treponema pallidum in normal and immune rabbits. Am J Syph Gonorrhea Vener Dis. 1949; 33(3):201-212.

15. Fieldsteel AH, Cox DL, Moeckli RA. Cultivation of virulent Treponema pallidum in tissue culture. Infect Immun. 1981;32(2):908-915.

16. Bjerke JR, Krogh HK, Matre R. In situ identification of mononuclear cells in cutaneous infiltrates in discoid lupus erythematosus, sarcoidosis and secondary syphilis. Acta Derm Venereol. 1981;61(5):371-380.

17. Tosca A, Lehou J, Hatjivasiliou M, Varelzidis A, Stratigos JD. Infiltrate of syphilitic lesions before and after treatment. Genitourin Med. 1988;64(5):289-293.

18. Van Voorhis WC, Barrett LK, Koelle DM, Nasio JM, Plummer FA, Lukehart SA. Primary and secondary syphilis lesions contain mRNA for Th1 cytokines. J Infect Dis. 1996;173(2):491-495.
19. McBroom RL, Styles AR, Chiu MJ, Clegg C, Cockerell CJ, Radolf JD. Secondary syphilis in persons infected with and not infected with HIV-1: a comparative immunohistologic study. Am J Dermatopathol. 1999;21(5):432-441.

20. Godornes C, Leader BT, Molini BJ, Centurion-Lara A, Lukehart SA. Quantitation of rabbit cytokine mRNA by real-time RT-PCR. Cytokine. 2007;38(1):1-7.

21. Leader BT, Godornes C, Van Voorhis WC, Lukehart SA. CD4+ Lymphocytes and gamma interferon predominate in local immune responses in early experimental syphilis. Infect Immun. 2007; 75(6):3021-3026

22. Hovind-Hougen K. Determination by means of electron microscopy of morphological criteria of value for classification of some spirochetes, in particular treponemes. Acta Pathol Microbiol Scand Suppl. 1976;(255):1-41.

23. Izard J, et al. Cryo-electron tomography elucidates the molecular architecture of Treponema pallidum, the syphilis spirochete. J Bacteriol. 2009; 191(24):7566-7580.

24. Liu J, Howell JK, Bradley SD, Zheng Y, Zhou ZH, Norris SJ. Cellular architecture of Treponema pallidum: novel flagellum, periplasmic cone, and cell envelope as revealed by cryo electron tomography. J Mol Biol. 2010;403(4):546-561.

25. Riley BS, Oppenheimer-Marks N, Hansen EJ, Radolf JD, Norgard MV. Virulent Treponema pallidum activates human vascular endothelial cells. J Infect Dis. 1992;165(3):484-493. 
26. Thomas DD, Navab M, Haake DA, Fogelman AM, Miller JN, Lovett MA. Treponema pallidum invades intercellular junctions of endothelial cell monolayers. Proc Natl Acad Sci U S A. 1988;85(10):3608-3612.

27. Juanpere-Rodero N, et al. Cell and tissue interactions of Treponema pallidum in primary and secondary syphilitic skin lesions: an ultrastructural study of serial sections [published online ahead of print July 7, 2011]. Ultrastruct Pathol. doi:10.3109/019131 23.2011.584498

28. Chung KY, Kim KS, Lee MG, Chang NS, Lee JB. Treponema pallidum induces up-regulation of interstitial collagenase in human dermal fibroblasts. Acta Derm Venereol. 2002;82(3):174-178.

29. Chapel TA. The signs and symptoms of secondary syphilis. Sex Transm Dis. 1980;7(4):161-164.

30. Mindel A, Tovey SJ, Timmins DJ, Williams P. Primary and secondary syphilis, 20 years' experience. 2. Clinical features. Genitourin Med. 1989;65(1):1-3.

31. Lee KH, Choi HJ, Lee MG, Lee JB. Virulent Treponema pallidum $47 \mathrm{kDa}$ antigen regulates the expression of cell adhesion molecules and binding of T-lymphocytes to cultured human dermal microvascular endothelial cells. Yonsei Med J. 2000; 41(5):623-633.

32. Van Voorhis WC, Barrett LK, Nasio JM, Plummer FA, Lukehart SA. Lesions of primary and secondary syphilis contain activated cytolytic T cells. Infect Immun. 1996;64(3):1048-1050.

33. Salazar JC, et al. Treponema pallidum elicits innate and adaptive cellular immune responses in skin and blood during secondary syphilis: a flow-cytometric analysis. J Infect Dis. 2007;195(6):879-887.

34. Stary G, et al. Host defense mechanisms in secondary syphilitic lesions: a role for IFN-gamma-/ IL-17-producing CD8+ T cells? Am J Pathol. 2010; 177(5):2421-2432.

35. Norgard MV, Riley BS, Richardson JA, Radolf JD. Dermal inflammation elicited by synthetic analogs of Treponema pallidum and Borrelia burgdorferi lipoproteins. Infect Immun. 1995;63(4):1507-1515.

36. Sellati TJ, et al. Treponema pallidum and Borrelia burgdorferi lipoproteins and synthetic lipopeptides activate monocytic cells via a CD14-dependent pathway distinct from that used by lipopolysaccharide. J Immunol. 1998;160(11):5455-5464.

37. Bos JD, Hamerlinck F, Cormane RH. T lymphoid cells in primary syphilis. Quantitative studies. $\mathrm{BrJ}$ Vener Dis. 1980;56(2):74-76.

38. Sellati TJ, Waldrop SL, Salazar JC, Bergstresser PR, Picker LJ, Radolf JD. The cutaneous response in humans to Treponema pallidum lipoprotein analogues involves cellular elements of both innate and adaptive immunity. J Immunol. 2001;166(6):4131-4140.

39. Salazar JC, Pope CD, Moore MW, Pope J, Kiely TG, Radolf JD. Lipoprotein-dependent and -independent immune responses to spirochetal infection. Clin Diagn Lab Immunol. 2005;12(8):949-958.

40. Brightbill HD, et al. Host defense mechanisms triggered by microbial lipoproteins through toll-like receptors. Science. 1999;285(5428):732-736.

41. Bouis DA, Popova TG, Takashima A, Norgard MV. Dendritic cells phagocytose and are activated by Treponema pallidum. Infect Immun. 2001;69(1):518-528.

42. Hertz CJ, et al. Microbial lipopeptides stimulate dendritic cell maturation via toll-like receptor 2 . J Immunol. 2001;166(4):2444-2450.

43. Shin JL, Chung KY, Kang JM, Lee TH, Lee MG. The effects of Treponema pallidum on human dendritic cells. Yonsei Med J. 2004;45(3):515-522.

44. Aliprantis AO, et al. Cell activation and apoptosis by bacterial lipoproteins through toll-like receptor-2. Science. 1999;285(5428):736-739.

45. Lien E, et al. Toll-like receptor 2 functions as a pattern recognition receptor for diverse bacterial products. J Biol Chem. 1999;274(47):33419-33425.

46. Babolin C, Amedei A, Ozolins D, Zilevica A, D'Elios MM, de Bernard M. TpF1 from Treponema pallidum activates inflammasome and promotes the development of regulatory T cells. J Immunol. 2011;187(3):1377-1384

47. Lukehart SA, Miller JN. Demonstration of the in vitro phagocytosis of Treponema pallidum by rabbit peritoneal macrophages. J Immunol. 1978;121(5):2014-2024.

48. Nelson RA, Mayer MM. Immobilization of Treponema pallidum in vitro by antibody produced in syphilitic infection. J Exp Med. 1949;89(4):369-393.

49. Bishop NH, Miller JN. Humoral immunity in experimental syphilis. II. The relationship of neutralizing factors in immune serum to acquired resistance. J Immunol. 1976;117(1):197-207.

50. Lukehart SA, Baker-Zander SA, Lloyd RM, Sell S. Characterization of lymphocyte responsiveness in early experimental syphilis. II. Nature of cellular infiltration and Treponema pallidum distribution in testicular lesions. J Immunol. 1980;124(1):461-467.

51. Shaffer JM, Baker-Zander SA, Lukehart SA. Opsonization of Treponema pallidum is mediated by immunoglobulin $G$ antibodies induced only by pathogenic treponemes. Infect Immun. 1993;61(2):781-784.

52. Baker-Zander SA, Shaffer JM, Lukehart SA. VDRL antibodies enhance phagocytosis of Treponema pallidum by macrophages. J Infect Dis. 1993; 167(5):1100-1105.

53. McKevitt M, et al. Genome scale identification of Treponema pallidum antigens. Infect Immun. 2005;73(7):4445-4450.

54. Hanff PA, Fehniger TE, Miller JN, Lovett MA. Humoral immune response in human syphilis to polypeptides of Treponema pallidum. J Immunol. 1982;129(3):1287-1291.

55. Lukehart SA, Baker-Zander SA, Gubish ER Jr. Identification of Treponema pallidum antigens: comparison with a nonpathogenic treponeme. J Immunol. 1982;129(2):833-838.

56. Baker-Zander SA, Hook EW 3rd, Bonin P, Handsfield $\mathrm{HH}$, Lukehart SA. Antigens of Treponema pallidum recognized by IgG and IgM antibodies during syphilis in humans. J Infect Dis. 1985;151(2):264-272.

57. Hensel U, Wellensiek HJ, Bhakdi S. Sodium dodecyl sulfate-polyacrylamide gel electrophoresis immunoblotting as a serological tool in the diagnosis of syphilitic infections. J Clin Microbiol. 1985;21(1):82-87

58. Sexually Transmitted Diseases Diagnostic Initiatives. About SDI. WHO web site. http://www. who.int/std_diagnostics/about_SDI/default.htm. Accessed September 21, 2011.

59. Young H, Moyes A, McMillan A, Robertson DH. Screening for treponemal infection by a new enzyme immunoassay. Genitourin Med. 1989;65(2):72-78.

60. Young H, Pryde J, Duncan L, Dave J. The Architect Syphilis assay for antibodies to Treponema pallidum: an automated screening assay with high sensitivity in primary syphilis. Sex Transm Infect. 2009; 85(1):19-23.

61. Knight CS, Crum MA, Hardy RW. Evaluation of the LIAISON chemiluminescence immunoassay for diagnosis of syphilis. Clin Vaccine Immunol. 2007; 14(6):710-713.

62. Centers for Disease Control and Prevention. Discordant results from reverse sequence syphilis screening - five laboratories, United States, 2006-2010. MMWR Morb Mortal Wkly Rep. 2011;60(5):133-137.

63. Riviere GR, et al. Identification of spirochetes related to Treponema pallidum in necrotizing ulcerative gingivitis and chronic periodontitis. $N$ Engl J Med. 1991;325(8):539-543

64. Bishop NH, Miller JN. Humoral immunity in experimental syphilis. I. The demonstration of resistance conferred by passive immunization. J Immunol. 1976;117(1):191-196.

65. Moore MW, et al. Phagocytosis of Borrelia burgdorferi and Treponema pallidum potentiates innate immune activation and induces gamma interferon production. Infect Immun. 2007;75(4):2046-2062.

66. Lukehart SA, Shaffer JM, Baker-Zander SA. A subpopulation of Treponema pallidum is resistant to phagocytosis: possible mechanism of persistence. J Infect Dis. 1992;166(6):1449-1453

67. Marra CM, et al. Cerebrospinal fluid abnormalities in patients with syphilis: association with clinical and laboratory features. J Infect Dis. 2004;189(3):369-376.

68. Marra CM. Deja vu all over again: when to perform a lumbar puncture in HIV-infected patients with syphilis. Sex Transm Dis. 2007;34(3):145-146.

69. Libois A, et al. HIV and syphilis: when to perform a lumbar puncture. Sex Transm Dis. 2007; 34(3):141-144.

70. Ghanem KG, Moore RD, Rompalo AM, Erbelding EJ, Zenilman JM, Gebo KA. Neurosyphilis in a clinical cohort of HIV-1-infected patients. AIDS. 2008;22(10):1145-1151.

71. Musher DM, Hamill RJ, Baughn RE. Effect of human immunodeficiency virus (HIV) infection on the course of syphilis and on the response to treatment. Ann Intern Med. 1990;113(11):872-881.

72. Taylor MM, Aynalem G, Olea LM, He P, Smith LV, Kerndt PR. A consequence of the syphilis epidemic among men who have sex with men (MSM): neurosyphilis in Los Angeles, 2001-2004. Sex Transm Dis. 2008;35(5):430-434.

73. Poliseli R, Vidal JE, Penalva De Oliveira AC, Hernandez AV. Neurosyphilis in HIV-infected patients: clinical manifestations, serum venereal disease research laboratory titers, and associated factors to symptomatic neurosyphilis. Sex Transm Dis. 2008; 35(5):425-429.

74. Marra CM, Tantalo LC, Sahi SK, Maxwell CL, Lukehart SA. CXCL13 as a cerebrospinal fluid marker for neurosyphilis in HIV-infected patients with syphilis. Sex Transm Dis. 2010;37(5):283-287.

75. Barbour AG, Burman N, Carter CJ, Kitten T, Bergstrom S. Variable antigen genes of the relapsing fever agent Borrelia hermsii are activated by promoter addition. Mol Microbiol. 1991;5(2):489-493.

76. Zhang JR, Hardham JM, Barbour AG, Norris SJ. Antigenic variation in Lyme disease borreliae by promiscuous recombination of VMP-like sequence cassettes. Cell. 1997;89(2):275-285.

77. Walker EM, Zampighi GA, Blanco DR, Miller JN, Lovett MA. Demonstration of rare protein in the outer membrane of Treponema pallidum subsp. pallidum by freeze-fracture analysis. J Bacteriol. 1989; 171(9):5005-5011.

78. Radolf JD, Norgard MV, Schulz WW. Outer membrane ultrastructure explains the limited antigenicity of virulent Treponema pallidum. Proc Natl Acad Sci US A. 1989;86(6):2051-2055.

79. Cox DL, et al. Surface immunolabeling and consensus computational framework to identify candidate rare outer membrane proteins of Treponema pallidum. Infect Immun. 2010;78(12):5178-5194.

80. Centurion-Lara A, et al. Treponema pallidum major sheath protein homologue $\mathrm{Tpr} K$ is a target of opsonic antibody and the protective immune response. J Exp Med. 1999;189(4):647-656.

81. Morgan CA, Molini BJ, Lukehart SA, Van Voorhis WC. Segregation of B and T cell epitopes of Treponema pallidum repeat protein $\mathrm{K}$ to variable and conserved regions during experimental syphilis infection. J Immunol. 2002;169(2):952-957.

82. Leader BT, Hevner K, Molini BJ, Barrett LK, Van Voorhis WC, Lukehart SA. Antibody responses elicited against the Treponema pallidum repeat proteins differ during infection with different isolates of Treponema pallidum subsp. pallidum. Infect Immun. 2003;71(10):6054-6057.

83. Morgan CA, Lukehart SA, Van Voorhis WC. Immunization with the N-terminal portion of Treponema pallidum repeat protein $\mathrm{K}$ attenuates syphi- 
litic lesion development in the rabbit model. Infect Immun. 2002;70(12):6811-6816.

84. Centurion-Lara A, Godornes C, Castro C, Van Voorhis WC, Lukehart SA. The tprK gene is heterogeneous among Treponema pallidum strains and has multiple alleles. Infect Immun. 2000;68(2):824-831.

85. Stamm LV, Bergen HL. The sequence-variable, single-copy tprK gene of Treponema pallidum Nichols strain UNC and street strain 14 encodes heterogeneous TprK proteins. Infect Immun. 2000 68(11):6482-6486.

86. LaFond RE, Centurion-Lara A, Godornes C, Van Voorhis WC, Lukehart SA. TprK sequence diversity accumulates during infection of rabbits with Treponema pallidum subsp. pallidum Nichols strain. Infect Immun. 2006;74(3):1896-1906.

87. Giacani L, et al. Antigenic variation in Treponema pallidum: TprK sequence diversity accumulates in response to immune pressure during experimental syphilis. IImmunol. 2010;184(7):3822-3829.

88. Centurion-Lara A, et al. Gene conversion: a mechanism for generation of heterogeneity in the $t p r K$ gene of Treponema pallidum during infection. Mol Microbiol. 2004;52(6):1579-1596.

89. LaFond RE, Molini BJ, Van Voorhis WC, Lukehart $\mathrm{SA}$. Antigenic variation of TprK $\mathrm{V}$ regions abrogates specific antibody binding in syphilis. Infect Immun. 2006;74(11):6244-6251.

90. Gjestland T. The Oslo study of untreated syphilis; an epidemiologic investigation of the natural course of the syphilitic infection based upon a restudy of the Boeck-Bruusgaard material. Acta Derm Venereol Suppl (Stockh). 1955;35(suppl 34):3-368.

91. Chesson HW, Heffelfinger JD, Voigt RF, Collins D. Estimates of primary and secondary syphilis rates in persons with HIV in the United States, 2002. Sex Transm Dis. 2005;32(5):265-269.

92. Workowski KA, Berman S, Centers for Disease Control and Prevention (CDC). Sexually transmitted diseases treatment guidelines, 2010. MMWR Recomm Rep. 2010;59(RR-12):1-110.

93. Centers for Disease Control and Prevention, Workowski KA, Berman SM. Sexually transmitted diseases treatment guidelines, 2006. MMWR Recomm Rep. 2006;55(RR-11):1-94.

94. Spindler HH, et al. Viagra, methamphetamine, and HIV risk: results from a probability sample of MSM, San Francisco. Sex Transm Dis. 2007;34(8):586-591.

95. Taylor MM, Aynalem G, Smith LV, Montoya J, Kerndt P. Methamphetamine use and sexual risk behaviours among men who have sex with men diagnosed with early syphilis in Los Angeles County. Int J STD AIDS. 2007;18(2):93-97.

96. Greenblatt RM, et al. Genital ulceration as a risk factor for human immunodeficiency virus infection. AIDS. 1988;2(1):47-50.

97. Sheffield JS, Wendel GD Jr, McIntire DD, Norgard MV. Effect of genital ulcer disease on HIV-1 coreceptor expression in the female genital tract. J Infect Dis. 2007;196(10):1509-1516.

98. Ghanem KG, Moore RD, Rompalo AM, Erbelding EJ, Zenilman JM, Gebo KA. Lumbar puncture in HIV-infected patients with syphilis and no neurologic symptoms. Clin Infect Dis. 2009;48(6):816-821.

99. de Almeida SM, et al. Cerebrospinal fluid human immunodeficiency virus viral load in patients with neurosyphilis. J Neurovirol. 2010;16(1):6-12.

100. Weintrob AC, et al. Syphilis co-infection does not affect HIV disease progression. Int J STD AIDS. 2010;21(1):57-59.

101.Sadiq ST, et al. The effects of early syphilis on CD4 counts and HIV-1 RNA viral loads in blood and semen. Sex Transm Infect. 2005;81(5):380-385.

102. Buchacz K, et al. Syphilis increases HIV viral load and decreases CD4 cell counts in HIV-infected patients with new syphilis infections. AIDS. 2004; 18(15):2075-2079

103. Kofoed K, Gerstoft J, Mathiesen LR, Benfield T.
Syphilis and human immunodeficiency virus (HIV)-1 coinfection: influence on CD4 T-cell count, HIV-1 viral load, and treatment response. Sex Transm Dis. 2006;33(3):143-148.

104. Palacios R, et al. Impact of syphilis infection on HIV viral load and CD4 cell counts in HIV-infected patients. J Acquir Immune Defic Syndr. 2007; 44(3):356-359.

105. Rolfs RT, et al. A randomized trial of enhanced therapy for early syphilis in patients with and without human immunodeficiency virus infection. The Syphilis and HIV Study Group. N Engl J Med. 1997; 337(5):307-314.

106.Ghanem KG, Erbelding EJ, Wiener ZS, Rompalo AM. Serological response to syphilis treatment in HIV-positive and HIV-negative patients attending sexually transmitted diseases clinics. Sex Transm Infect. 2007;83(2):97-101.

107. Horberg MA, Ranatunga DK, Quesenberry CP, Klein DB, Silverberg MJ. Syphilis epidemiology and clinical outcomes in HIV-infected and HIV-uninfected patients in Kaiser Permanente Northern California. Sex Transm Dis. 2010;37(1):53-58.

108.Lukehart SA, Hook EW, Baker-Zander SA, Collier $\mathrm{AC}$, Critchlow CW, Handsfield HH. Invasion of the central nervous system by Treponema pallidum: implications for diagnosis and treatment. Ann Intern Med. 1988;109(11):855-862.

109. Marra CM, et al. Normalization of cerebrospinal fluid abnormalities after neurosyphilis therapy: does HIV status matter? Clin Infect Dis. 2004;38(7):1001-1006.

110. Marra CM, Longstreth WT Jr, Maxwell CL, Lukehart SA. Resolution of serum and cerebrospinal fluid abnormalities after treatment of neurosyphilis. Influence of concomitant human immunodeficiency virus infection. Sex Transm Dis. 1996;23(3):184-189.

111. Mashkilleyson AL, Gomberg MA, Mashkilleyson N, Kutin SA. Treatment of syphilis with azithromycin. Int J STD AIDS. 1996;7(suppl 1):13-15.

112.Gruber F, Kastelan M, Cabrijan L, Simonic E, Brajac I. Treatment of early syphilis with azithromycin. J Chemother. 2000;12(3):240-243.

113.Hook EW 3rd, Martin DH, Stephens J, Smith BS, Smith K. A randomized, comparative pilot study of azithromycin versus benzathine penicillin $G$ for treatment of early syphilis. Sex Transm Dis. 2002; 29(8):486-490.

114. Riedner G, et al. Single-dose azithromycin versus penicillin $G$ benzathine for the treatment of early syphilis. N Engl J Med. 2005;353(12):1236-1244.

115.Kiddugavu MG, et al. Effectiveness of syphilis treatment using azithromycin and/or benzathine penicillin in Rakai, Uganda. Sex Transm Dis. 2005; 32(1):1-6.

116. Hook EWI, et al. A phase III equivalence trial of azithromycin versus benzathine penicillin for treatment of early syphilis. J Infect Dis. 2010; 201(11):1729-1735

117. Stamm LV, Stapleton JT, Bassford PJ Jr. In vitro assay to demonstrate high-level erythromycin resistance of a clinical isolate of Treponema pallidum. Antimicrob Agents Chemother. 1988;32(2):164-169.

118. Stapleton JT, Stamm LV, Bassford PJ Jr. Potential for development of antibiotic resistance in pathogenic treponemes. Rev Infect Dis. 1985; 7(suppl 2):S314-S317.

119.Stamm LV, Parrish EA. In-vitro activity of azithromycin and CP-63,956 against Treponema pallidum. J Antimicrob Chemother. 1990;25(suppl A):11-14.

120.Stamm LV, Bergen HL. A point mutation associated with bacterial macrolide resistance is present in both 23S rRNA genes of an erythromycin-resistant Treponema pallidum clinical isolate. Antimicrob Agents Chemother. 2000;44(3):806-807.

121. Lukehart SA, et al. Macrolide resistance in Treponema pallidum in the United States and Ireland. N Engl J Med. 2004;351(2):154-158.

122. Mitchell SJ, et al. Azithromycin-resistant syphilis infection: San Francisco, California, 2000-2004. Clin Infect Dis. 2006;42(3):337-345.

123. Katz KA, et al. Molecular epidemiology of syphilis - San Francisco, 2004-2007. Sex Transm Dis. 2010;37(10):660-663.

124. Matejkova P, et al. Macrolide treatment failure in a case of secondary syphilis: a novel A2059G mutation in the 23S rRNA gene of Treponema pallidum subsp. pallidum. J Med Microbiol. 2009; 58(pt 6):832-836

125.Zhou P, et al. Azithromycin treatment failure among primary and secondary syphilis patients in Shanghai. Sex Transm Dis. 2010;37(11):726-729.

126.Pillay A, et al. Molecular subtyping of Treponema pallidum subspecies pallidum. Sex Transm Dis. 1998; 25(8):408-414.

127. Sutton MY, et al. Molecular subtyping of Treponema pallidum in an Arizona County with increasing syphilis morbidity: use of specimens from ulcers and blood. J Infect Dis. 2001;183(11):1601-1606.

128. Pillay A, et al. Molecular typing of Treponema pallidum in South Africa: cross-sectional studies. J Clin Microbiol. 2002;40(1):256-258.

129. Pope V, et al. Molecular subtyping of Treponema pallidum from North and South Carolina. J Clin Microbiol. 2005;43(8):3743-3746.

130. Molepo J, Pillay A, Weber B, Morse SA, Hoosen AA. Molecular typing of Treponema pallidum strains from patients with neurosyphilis in Pretoria, South Africa. Sex Transm Infect. 2007;83(3):189-192.

131. Florindo C, Reigado V, Gomes JP, Azevedo J, Santo I, Borrego MJ. Molecular typing of Treponema pallidum clinical strains from Lisbon, Portugal. J Clin Microbiol. 2008;46(11):3802-3803.

132. Castro R, Prieto E, Aguas MJ, Manata MJ, Botas J, Pereira FM. Molecular subtyping of Treponema pallidum subsp. pallidum in Lisbon, Portugal. J Clin Microbiol. 2009;47(8):2510-2512.

133. Cole MJ, Chisholm SA, Palmer HM, Wallace LA, Ison CA. Molecular epidemiology of syphilis in Scotland. Sex Transm Infect. 2009;85(6):447-451.

134.Martin IE, Gu W, Yang Y, Tsang RS. Macrolide resistance and molecular types of Treponema pallidum causing primary syphilis in Shanghai, China. Clin Infect Dis. 2009;49(4):515-521.

135. Marra CM, et al. Enhanced molecular typing of Treponema pallidum: geographical distribution of strain types and association with neurosyphilis. J Infect Dis. 2010;202(9):1380-1388.

136. Marra CM, et al. Antibiotic selection may contribute to increases in macrolide-resistant Treponema pallidum. J Infect Dis. 2006;194(12):1771-1773.

137. Stokes JH, Beerman H, Ingram NR. Modern Clinical Syphilology. Philadelphia, Pennsylvania, USA: W.B. Saunders; 1944

138. Tantalo LC, Lukehart SA, Marra CM. Treponema pallidum strain-specific differences in neuroinvasion and clinical phenotype in a rabbit model. J Infect Dis. 2005;191(1):75-80.

139.Lukehart SA. Prospects for development of a treponemal vaccine. Rev Infect Dis. 1985; 7(suppl 2):S305-S313.

140. Cullen PA, Cameron CE. Progress towards an effective syphilis vaccine: the past, present and future. Expert Rev Vaccines. 2006;5(1):67-80.

141. Miller JN. Immunity in experimental syphilis. VI. Successful vaccination of rabbits with Treponema pallidum, Nichols strain, attenuated by $\gamma$-irradiation. J Immunol. 1973;110(5):1206-1215.

142. Cameron CE, Castro C, Lukehart SA, Van Voorhis WC. Function and protective capacity of Treponema pallidum subsp. pallidum glycerophosphodiester phosphodiesterase. Infect Immun. 1998;66(12):5763-5770.

143. Cameron CE, Lukehart SA, Castro C, Molini B, Godornes C, Van Voorhis WC. Opsonic potential, protective capacity, and sequence conservation of the Treponema pallidum subspecies pallidum $\mathrm{T}$ p92. J Infect Dis. 2000;181(4):1401-1413. 
144. Sun ES, Molini BJ, Barrett LK, Centurion-Lara A, Lukehart SA, Van Voorhis WC. Subfamily I Treponema pallidum repeat protein family: sequence variation and immunity. Microbes Infect. 2004;6(8):725-737.

145. Giacani L, et al. Immunological evaluation and cellular location analysis of the TprI antigen of Treponema pallidum subsp. pallidum. Infect Immun. 2005;73(6):3817-3822.

146. Merritt HH, Adams RD, Solomon HC. Neurosyphi- lis. New York, New York, USA: Oxford University Press; 1946.

147. Clark EG, Danbolt N. The Oslo study of the natural history of untreated syphilis; an epidemiologic investigation based on a restudy of the Boeck-Bruusgaard material; a review and appraisal. J Chronic Dis. 1955;2(3):311-344.

148.Golden MR, Marra CM, Holmes KK. Update on syphilis: resurgence of an old problem. JAMA. 2003;
290(11):1510-1514.

149.Martin IE, et al. Molecular characterization of syphilis in patients in Canada: azithromycin resistance and detection of Treponema pallidum DNA in whole-blood samples versus ulcerative swabs. JClin Microbiol. 2009;47(6):1668-1673.

150.Peng R-R, et al. Molecular typing of Treponema pallidum causing early syphilis in China: a cross-sectional study. Sex Transm Dis. In press. 